\title{
INTRAOPERATIVE SPONTANEOUS RUPTURE OF UTERINE VARICOSE VEIN
}

\author{
Dubravko Habek \\ Clinical Department of Obstetrics and Gynecology, Sveti Duh University Hospital, \\ Croatian Catholic University, Zagreb, Croatia
}

Dear Editor,

Spontaneous, non-traumatic rupture of pelvic (uterine) varicose veins in pregnancy and delivery is a very rare and unpredictable complication associated with a high maternal morbidity and mortality of up to $30 \%$ due to hemoperitoneum and hemorrhagic shock. Clinically, rupture of pelvic (uterine) varicose vein mostly mimics placental abruption or uterine rupture ${ }^{1-3}$.

In a 35-year-old tertipara free from comorbidity, repeat elective cesarean section in spinal anesthesia was performed in $39^{\text {th }}$ week of gestation because of previous two cesarean sections and transverse fetal lie. The procedure proceeded uneventfully, a healthy, eutrophic neonate was born, and there were no intraabdominal adhesions. During hysterotomy suture, there was constant efflux of dark blood from the left iliac fossa. Therefore, the uterus was exteriorized to reveal a varicose tubo-ovarian conglomerate at a broad, perforated, abundantly bleeding varicocele posteriorly, adjacent to the uterus. Considering this finding and inability to place sutures along with the oxidized cellulose strip just placed on the vein, which was fragile and breakable, left-sided adnexectomy was performed. However, there was massive bleeding also from descending varicose uterine veins (pelvic varicocele), therefore sutures according to O'Leary were made, but failed due to varicose vein breaks. Hemostatic sutures

Correspondence to: Prof. Dubravko Habek, $M D, P h D$, Clinical Department of Obstetrics and Gynecology, Sveti Duh University Hospital, Sveti Duh 64, HR-10000 Zagreb, Croatia E-mail: dubravko.habek@os.t-com.hr,dhabek@unicath.hr Received July 7,2016, accepted November 30, 2016 were placed for bleeding from uterine edges, but abundant bleeding continued. Because of uncontrollable hemorrhage, maternal age and multiparity, total hysterectomy with adequate hemodynamic replacement was performed, upon the patient's consent. The postoperative course was normal and the patient was discharged from the hospital on the fifth day of the puerperium.

Varices of the broad ligament, superficial uterine veins and utero-ovarian ligament have been described in several case reports ${ }^{3,4}$. Urgent laparotomy is indicated for vital indications, with hemostasis by ligature (uterine or internal iliac artery ligation), oxidized cellulose, or rarely hysterectomy, thereby respecting maternal age, parity, site and intensity of bleeding, shock development ${ }^{2}$, as in the case of uncontrolled bleeding presented. A recently reported case of percutaneous embolization of ruptured varicocele is an option of conservative treatment aiming at uterus preservation ${ }^{5}$, which requires trained interventional radiology team, which was not available in our hospital at that time.

\section{References}

1. Lim PS, Ng SP, Shafiee MN, Kampan N, Jamil MA. Spontaneous rupture of uterine varicose veins: a rare cause for obstetric shock. J Obstet Gynaecol Res. 2014;40(6):1791-4. doi: 10.1111/jog.12402

2. Hashimoto K, Tabata C, Ueno Y, Fukuda H, Shimoya K, Murata $\mathrm{Y}$. Spontaneous rupture of uterine surface varicose veins in pregnancy: a case report. J Reprod Med. 2006;51(9):722-4.

3. Nakaya Y, Itoh H, Muramatsu K, Otome M, Kobayashi Y, Hirai K, Uchida T, Suzuki K, Sugihara K, Kanayama N. A case of spontaneous rupture of a uterine superficial varicose vein in 
midgestation. J Obstet Gynaecol Res. 2011;37(8):1149-53. doi: 10.1111/j.1447-0756.2010.01489.x. Epub 2011 Apr 19.

4. Giulini S, Zanin R, Volpe A. Hemoperitoneum in pregnancy from a ruptured varix of broad ligament. Arch Gynecol Obstet. 2010;282(4):459-61. doi: 10.1007/s00404-010-1411-7. Epub 2010 Mar 3.
5. Diaz-Murillo R, Tobias-Gonzales P, Lopez-Magallon S, Magdaleno-Dans F, Bartha JL. Spontaneous hemoperitoneum due to rupture of uterine varicose vein during labor successfully treated by percutaneous embolization. Case Report Obstet Gynecol. 2014;2014:580364.

doi: $10.1155 / 2014 / 580364$ 